\title{
Load Shedding Apply Neural Network and Power Sensitivity Theory
}

\author{
L.T. Nghia ${ }^{1}$, T.T. Giang ${ }^{1}$, Q.H. Anh $^{1}$, P.T.T. Binh ${ }^{2}$ \\ Bui.NguyenXuan. $\mathrm{Vu}^{1}$ \\ ${ }^{1}$ Faculty of Electrical and Electronics Engineering, HCMC University of Technology and Education \\ Hochiminh city, Vietnam \\ ${ }^{2}$ Faculty of Electrical and Electronics Engineering, HCMC University of Technology \\ Hochiminh city, Vietnam
}

\begin{abstract}
This paper proposed the method load shedding on the basis of the combination of Generalized Regression Neural Network, power sensitivity theory and Phase Electrical Distance theories to recover the frequency to allowable limit in the event loss a generator occurring in the electric system. The phase electrical distance calculation intended to calculate the distance between the generator outage and the load to align the load buses in ascending. The phase electrical distance sequence as compared to the fault generator. From there, the loads on the buses which are near the generator outage will be cut firstly, then the next loads until the system return to stable. The effectiveness of the proposed method are tested on the IEEE 39 Bus New England 10 Generators, which demonstrated the effective the proposed method.
\end{abstract}

Keywords: Load Shedding, Phase Electrical Distance, Power Sensitivity, Neural Network, Frequency Control.

\section{INTRODUCTION.}

Load shedding is an effective method for restoring electrical system frequencies by reducing the load to suit the power supply. Most of the studies related to load shedding are based on rate change of frequency and voltage of the power system.

$\mathrm{H}$. Bevrani and et al [1] presented an overview of the key issues in the use of frequency rate change $(\mathrm{df} / \mathrm{dt})$ in power system emergency control schemes. The role of $\mathrm{df} / \mathrm{dt}$ in designing effective under frequency load shedding (UFLS) plan was discussed. The impact of new variable renewable sources (such as wind and solar units) on system frequency gradient is analyzed, and the need for the revising of frequency performance standards, re-tuning of automatic UFLS relays, and use of $\Delta \mathrm{f} / \Delta \mathrm{t}$ rather than $\mathrm{df} / \mathrm{dt}$ are emphasized.

Urban Rudez and et al [2] studied a novel approach to underfrequency load shedding is using the frequency second derivative as a source of information for a forecast of the frequency trajectory. A Newton method based approximation and the interpolation of the frequency second derivative are continuously performed in order to forecast the minimum frequency value using a numerical integration.

F. Shokooh and et al [3] introduced the new technology of intelligent load shedding application in a large industrial facility.

Conventional methods of system load shedding often have to wait until the frequency drops below the allowable threshold to make the load shedding decision. However, due to the complexity of the power system, it is imperative to treat it promptly after a fault in order to minimize the damage, to improve the frequency response and to reduce the risk of unstable electric system.

This paper proposes the method of load shedding under predesigned load shedding rules based on phase electrical distance method and power sensitivity theory. ANN neural networks are used to identify and classify load shedding control strategies based on the designed rules. The effectiveness of the proposed method has been tested on the IEEE 39 Bus New England.

\section{MATERIALS AND METHODS.}

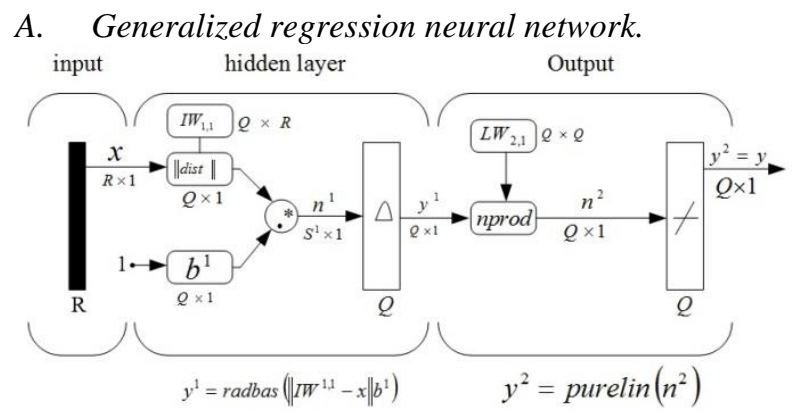

Fig. 1. Generalized regression neural network.

GRNN (Generalized Regression Neural Network) is a powerful tool in the application for identification problems. GRNN is basically the same as fig. 1 including input layer, radial function hidden layer and linear output layer. Neuron network operation must include the spread parameter whose optimum value is determined by the experimental error.

\section{B. Phase electrical distance [4]}

The definition of phase electrical distance between the two nodes by using the elements of the matrix $[\delta \theta / \delta \mathrm{P}]$ is the inverse matrix from the power sensitivity matrix $[\delta \mathrm{P} / \delta \theta]$, as follows:

$\mathrm{D}_{\mathrm{P}}(\mathrm{i}, \mathrm{j})=\left(\delta \theta_{\mathrm{i}} / \delta \mathrm{P}_{\mathrm{i}}\right)+\left(\delta \theta_{\mathrm{j}} / \delta \mathrm{P}_{\mathrm{j}}\right)-\left(\delta \theta_{\mathrm{j}} / \delta \mathrm{P}_{\mathrm{i}}\right)-\left(\delta \theta_{\mathrm{i}} / \delta \mathrm{P}_{\mathrm{j}}\right)$

The components $[\delta \theta / \delta \mathrm{P}]$ are extracted from the Jacobian matrix. There are two interpretations of the phase electrical distance:

$$
D_{P}(i, j)=\frac{\delta \theta_{i}}{\delta P_{i}}+\frac{\delta \theta_{j}}{\delta P_{j}}-\frac{\delta \theta_{j}}{\delta P_{i}}-\frac{\delta \theta_{i}}{\delta P_{j}}
$$

Write this distance in another way:

$$
D_{P}(i, j)=\frac{\delta \theta_{j}}{\delta P_{j}}-\frac{\delta \theta_{i}}{\delta P_{j}}+\frac{\delta \theta_{i}}{\delta P_{i}}-\frac{\delta \theta_{j}}{\delta P_{i}}
$$


$\left(\frac{\delta \theta_{j}}{\delta P_{j}}-\frac{\delta \theta_{i}}{\delta P_{j}}\right)$ is phase difference between $\mathrm{j}$ and $\mathrm{i}$ caused by a active power injection in $\mathrm{j}$.

$\left(\frac{\delta \theta_{i}}{\delta P_{i}}-\frac{\delta \theta_{j}}{\delta P_{i}}\right)$ is phase difference between $\mathrm{i}$ and $\mathrm{j}$ caused by a active power injection in $\mathrm{i}$.

Then else:

$$
D_{P}(i, j)=\frac{\delta \theta_{j}}{\delta P_{j}}-\frac{\delta \theta_{j}}{\delta P_{i}}+\frac{\delta \theta_{i}}{\delta P_{i}}-\frac{\delta \theta_{i}}{\delta P_{j}}
$$

$\left(\frac{\delta \theta_{j}}{\delta P_{j}}-\frac{\delta \theta_{j}}{\delta P_{i}}\right)$ is variation in phase of $\mathrm{j}$ caused by a active power transit from $\mathrm{j}$ to $\mathrm{i}$.

$\left(\frac{\delta \theta_{i}}{\delta P_{i}}-\frac{\delta \theta_{i}}{\delta P_{j}}\right)$ is variation in phase of $\mathrm{i}$ caused by a active power transit from $\mathrm{i}$ to $\mathrm{j}$.

Two nodes electrically very close will always have a very small phase difference corresponding to the small distance D. Therefore, in the event of a loss of generator, it should be cut the load at the buses which near the generator in advance.

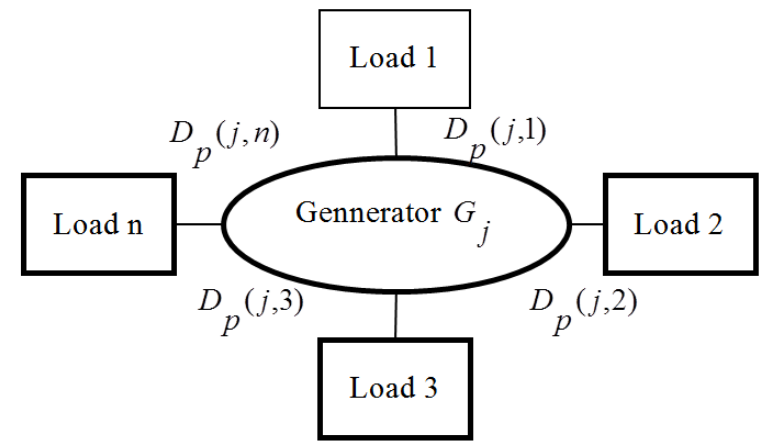

Fig. 2. The block diagram of the relationship between the generator $j$ and the loads

With: $D_{P}(j, 1)<D_{P}(j, 2)<D_{P}(j, 3) \ldots<D_{P}(j, n)$

Prioritized load shedding: Load $1 \rightarrow \operatorname{Load} 2 \rightarrow \operatorname{Load} 3 \rightarrow \ldots$ $\rightarrow$ Load $n$

\section{PROPOSED METHODS.}

\section{A. Set up load shedding program.}

Load shedding are based on three main factors: the timing, the amount of load to be shed and the location of load shedding

The timing: The system data is sent to the control center for continuous measurement, when the system frequency is within the allowable range of $59.7 \mathrm{~Hz}<\mathrm{f}<60.3 \mathrm{~Hz}$, the system frequency is within the allowable value, whereas if the system frequency is outside of the allowable range, the load shedding program will start, the neuron function will be activated to identify the generator with the fault and the load shedding sequence. The time is calculated after the time of the incident is $300 \mathrm{~ms}$. This interval includes time intervals: measurement of data acquisition, data transfer, data processing, and load circuit breaker operation. [5]

The amount of load to be shed: After obtaining the load shedding sequence list for each generator failure, use the offline
PowerWorld simulation software to shed for each generator in trouble at different load levels. (including 41 load levels from $60 \%$ to $100 \%$ ). Dismissed until the rotor angle, frequency and voltage of the buses are within the allowable range of stopping, so that for each case the incident will have the number of load shedding corresponding to that case. The incident data collected would correspond to a number of load shedding from the trained neuron function.

Location of load shedding: Use phase electrical distance for calculating distance between nodes. The load shedding position will be based on the distances from the generator outage (generator bus) to the remaining load buses to the load shedding order, or in other words the priority of the nodes closer to the generator will be first off, because these load nodes directly affect the generator is the most trouble.

The flowchart load shedding process is shown in Fig. 3 and 4.

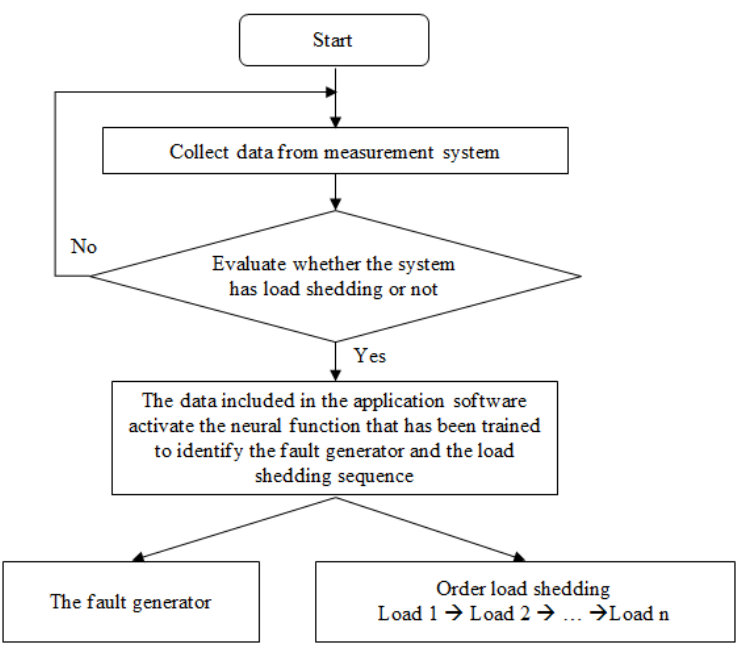

Fig. 3. Flowchart load shedding online

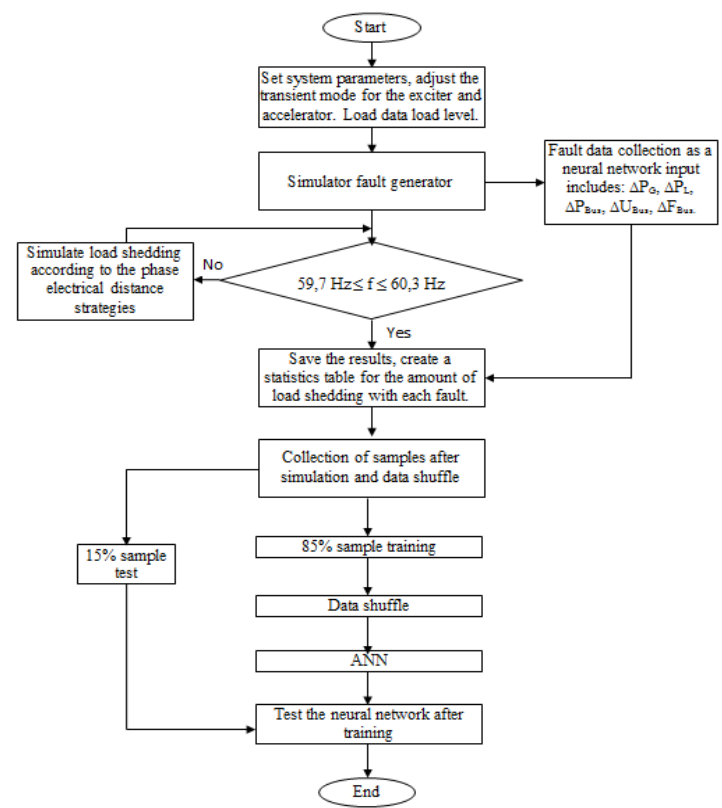

Fig. 4. Flowchart simulator sampling and neural network training

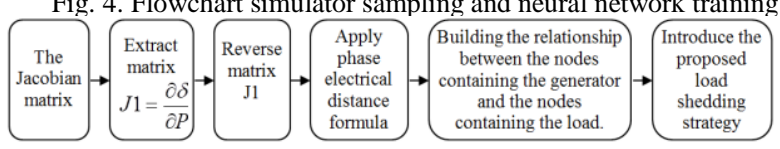

Fig. 5. The process of developing a load shedding strategy 
The process of developing a load shedding strategy, including steps:

From: $\mathrm{D}_{\mathrm{p}}(\mathrm{i}, \mathrm{j})=\left(\delta \theta_{\mathrm{i}} / \delta \mathrm{P}_{\mathrm{i}}\right)+\left(\delta \theta_{\mathrm{j}} / \delta \mathrm{P}_{\mathrm{j}}\right)-\left(\delta \theta_{\mathrm{j}} / \delta \mathrm{P}_{\mathrm{i}}\right)-\left(\delta \theta_{\mathrm{i}} / \delta \mathrm{P}_{\mathrm{j}}\right)$, with $\left(\delta \theta_{\mathrm{i}} / \delta \mathrm{P}_{\mathrm{i}}\right),\left(\delta \theta_{\mathrm{j}} / \delta \mathrm{P}_{\mathrm{j}}\right),\left(\delta \theta_{\mathrm{j}} / \delta \mathrm{P}_{\mathrm{i}}\right)$ and $\left(\delta \theta_{\mathrm{i}} / \delta \mathrm{P}_{\mathrm{j}}\right)$ are the corresponding elements in row i colum $\mathrm{j}$ in matrix [J1].

The Jacobian matrix has the following general form:

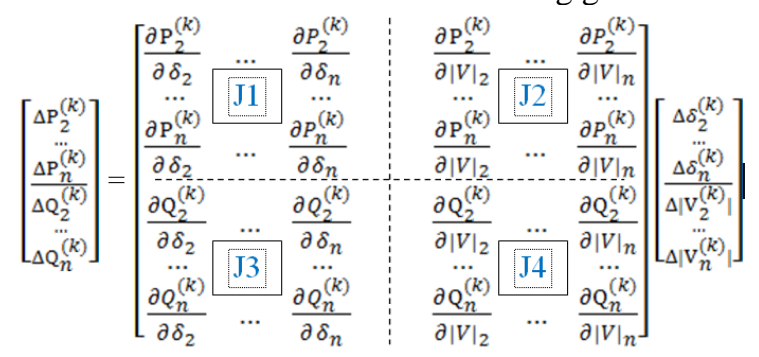

Fig. 6. General Jacobian matrix

Step 1: Extract the Jacobian matrix J1

Step 2: Inverse J1

Step 3: Apply phase electrical distance formula

Step 4: Building the relationship between the nodes containing the generator and the nodes containing the load.

Step 5: Arranges the order of the load shedding with the corresponding generator failure.

\section{B. Application ANN to identify the failure.}

Identification of failure in electrical systems is often difficult due to its complexity. Traditional failure identification methods are often unsuitable, which can cause problems not to be resolved in time to endanger the system. Thus, the ANN method with advantages of computational speed as well as efficiency will best solve these difficult problems that other traditional methods cannot solve.

First, need to build data sets for ANN learning. This database is based on parameters at different load levels of the system (rate change of generator power, load power, voltage at buses, power variation on line, rate change of frequency at buses). The database must meet the following requirements:

The database must fully display the status of the operation and must show all the various failure scenarios.

The database created should ensure objectivity of the parameters of the test power system.

The process of creating a database based on simulation PowerWorld and is done through the following stages:

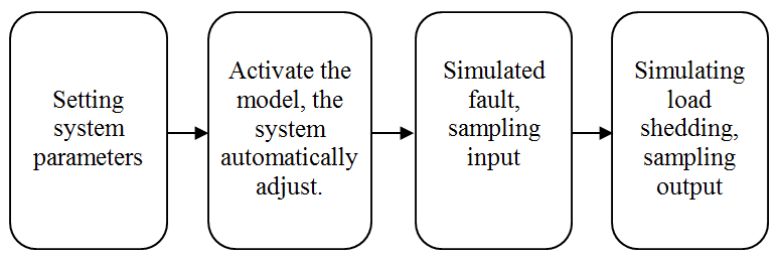

Fig. 7. Simulation steps for input, output sampling

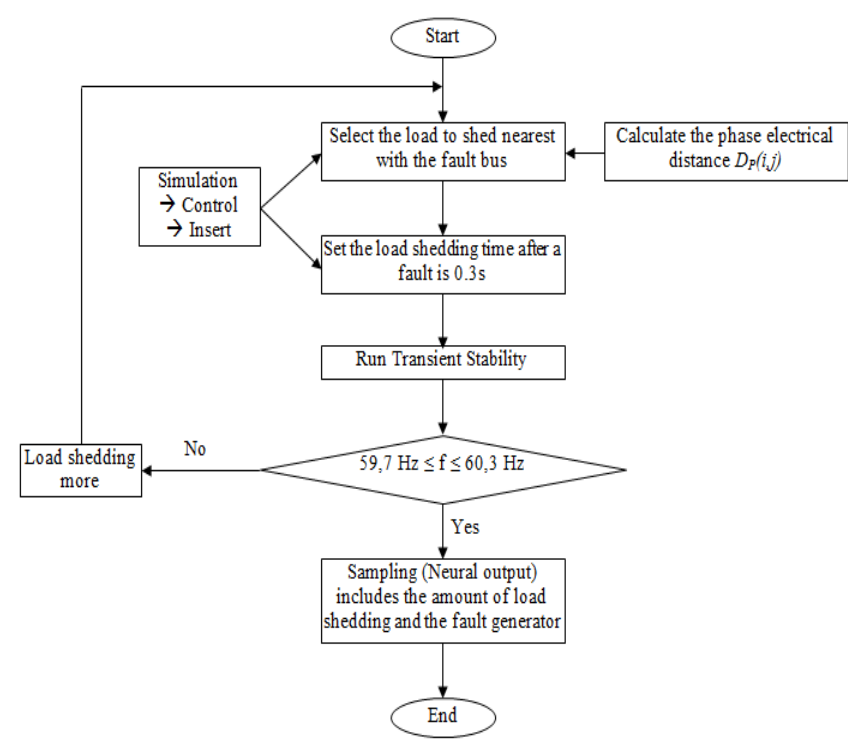

Fig. 8. Sampling process

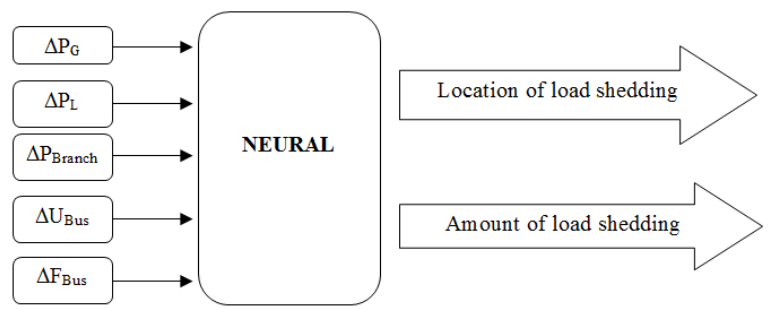

Fig. 9. Neural network training model with inputs and outputs

IV. TESTING ON THE IEEE 39 BUS NEW ENGLAND

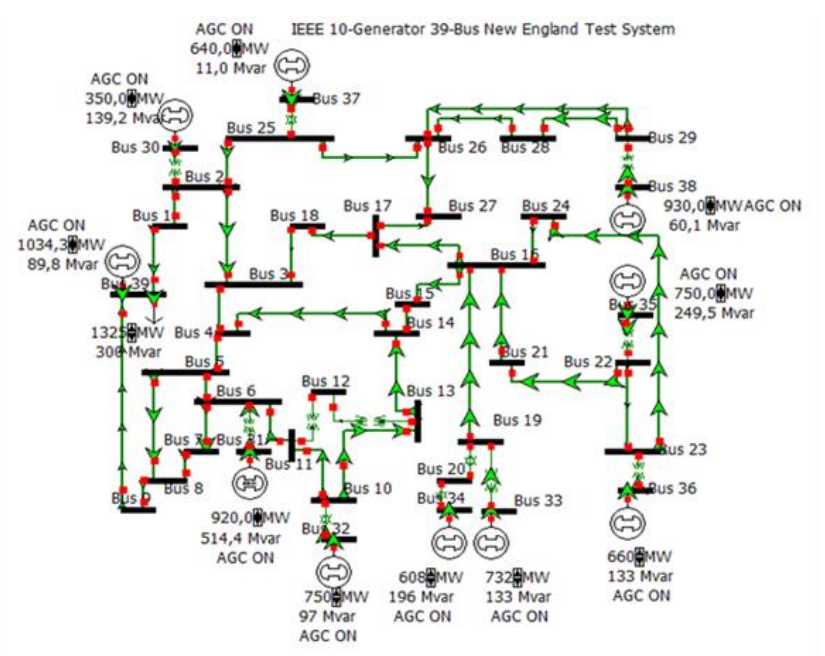

Fig. 10. The IEEE 39 bus New England

The proposed method is tested on The IEEE 39 bus New England, using Powerworld software to collect samples and Matlab software for neural network training.

A. Calculate the phase electrical distance.

The phase electrical distance calculation is done in the following steps:

Step 1: Take the Jacobian matrix J1 from Powerworld 


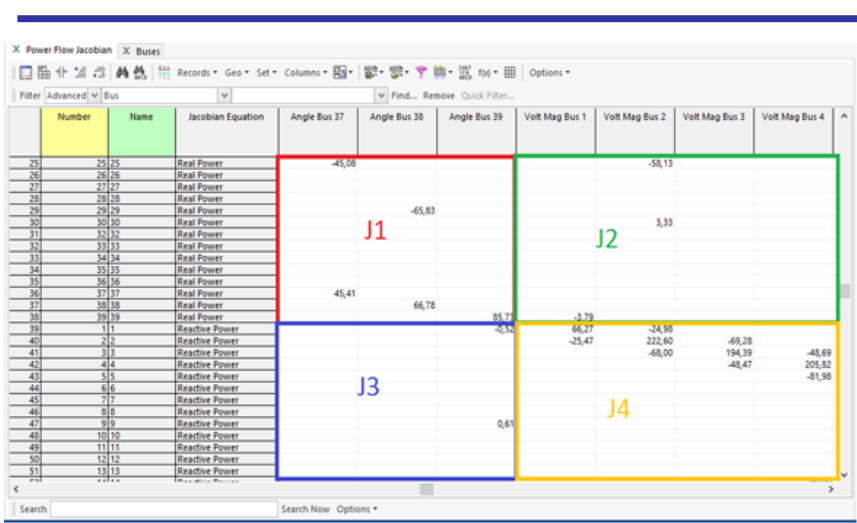

Fig. 11. The Jacobian matrix $\mathrm{J} 1$.

Step 2: Use the inv function of matlab to invert the matrix

Step 3: Apply phase electrical distance formula: $\mathrm{D}_{\mathrm{p}}(\mathrm{j}, \mathrm{i})=$ $\mathrm{D}_{\mathrm{p}}(\mathrm{i}, \mathrm{j})=\left(\delta \theta_{\mathrm{i}} / \delta \mathrm{P}_{\mathrm{i}}\right)+\left(\delta \theta_{\mathrm{j}} / \delta \mathrm{P}_{\mathrm{j}}\right)-\left(\delta \theta_{\mathrm{j}} / \delta \mathrm{P}_{\mathrm{i}}\right)-\left(\delta \theta_{\mathrm{i}} / \delta \mathrm{P}_{\mathrm{j}}\right)$

From the above formula, use the matlab software to set the matrix related to the phase electrical distance between the nodes in the network together, called the matrix $\mathrm{D}_{\mathrm{p}}$.

Step 4: From the relational parameters between the buses in the system to the phase electrical distance, the relationship between the nodes containing the generator and the nodes containing the load is shown in Table 1.

TABLE 1. Table summarizes the relationship between the nodes containing the generator and the nodes containing the load on phase electrical distance.

\begin{tabular}{|l|l|l|l|l|l|l|l|l|l|}
\hline & Bus 30 & Bus 32 & Bus 33 & Bus 34 & Bus 35 & Bus 36 & Bus 37 & Bus 38 & Bus 39 \\
\hline
\end{tabular}

\begin{tabular}{|l|l|l|l|l|l|l|l|l|l|}
\hline Bus 3 & 0.027 & 0.041 & 0.047 & 0.064 & 0.045 & 0.057 & 0.040 & 0.065 & 0.038 \\
\hline Bus 4 & 0.037 & 0.031 & 0.050 & 0.067 & 0.047 & 0.060 & 0.048 & 0.072 & 0.038 \\
\hline Bus 7 & 0.045 & 0.033 & 0.058 & 0.075 & 0.055 & 0.068 & 0.056 & 0.080 & 0.037 \\
\hline Bus 8 & 0.044 & 0.033 & 0.057 & 0.075 & 0.055 & 0.067 & 0.055 & 0.080 & 0.035 \\
\hline Bus 12 & 0.061 & 0.041 & 0.071 & 0.088 & 0.069 & 0.081 & 0.072 & 0.096 & 0.059 \\
\hline Bus 15 & 0.041 & 0.041 & 0.039 & 0.056 & 0.036 & 0.048 & 0.051 & 0.071 & 0.047 \\
\hline Bus 16 & 0.039 & 0.044 & 0.031 & 0.048 & 0.029 & 0.041 & 0.048 & 0.067 & 0.046 \\
\hline Bus 18 & 0.034 & 0.045 & 0.043 & 0.060 & 0.041 & 0.053 & 0.044 & 0.064 & 0.044 \\
\hline Bus 20 & 0.070 & 0.074 & 0.028 & 0.018 & 0.060 & 0.072 & 0.079 & 0.097 & 0.077 \\
\hline Bus 21 & 0.049 & 0.053 & 0.041 & 0.058 & 0.023 & 0.039 & 0.058 & 0.076 & 0.056 \\
\hline Bus 23 & 0.056 & 0.061 & 0.048 & 0.066 & 0.021 & 0.024 & 0.065 & 0.084 & 0.063 \\
\hline Bus 24 & 0.044 & 0.048 & 0.036 & 0.053 & 0.030 & 0.041 & 0.053 & 0.071 & 0.051 \\
\hline Bus 25 & 0.027 & 0.054 & 0.058 & 0.075 & 0.055 & 0.068 & 0.022 & 0.061 & 0.045 \\
\hline Bus 26 & 0.040 & 0.058 & 0.056 & 0.074 & 0.054 & 0.066 & 0.041 & 0.042 & 0.053 \\
\hline Bus 27 & 0.040 & 0.054 & 0.050 & 0.067 & 0.048 & 0.060 & 0.044 & 0.053 & 0.051 \\
\hline Bus 28 & 0.065 & 0.083 & 0.082 & 0.099 & 0.079 & 0.092 & 0.067 & 0.026 & 0.079 \\
\hline Bus 29 & 0.067 & 0.085 & 0.084 & 0.101 & 0.081 & 0.093 & 0.068 & 0.015 & 0.080 \\
\hline Bus 39 & 0.053 & 0.062 & 0.078 & 0.095 & 0.075 & 0.087 & 0.066 & 0.094 & 0.000 \\
\hline
\end{tabular}

Step 5: Arranges the order of the load shedding with the corresponding generators failure.
TABLE 2. Proposed load shedding strategy

\begin{tabular}{|c|c|c|c|c|c|c|c|c|c|}
\hline $\mathrm{Bl}$ & $\begin{array}{c}\text { Bus } \\
30\end{array}$ & $\begin{array}{l}\text { Bus } \\
32\end{array}$ & us & Bus & $\begin{array}{c}\text { Bus } \\
35\end{array}$ & us & us & $\begin{array}{l}3 \text { us } \\
38\end{array}$ & $\begin{array}{l}\text { us } \\
9\end{array}$ \\
\hline 1 & $\begin{array}{c}\text { Load } \\
25\end{array}$ & & & & & & & & 9 \\
\hline 2 & $\begin{array}{c}\text { Load } \\
3 \\
\end{array}$ & 7 & 10 & & $\begin{array}{l}\text { Load } \\
21\end{array}$ & & $\begin{array}{c}\text { Load } \\
3 \\
\end{array}$ & & $\begin{array}{l}\text { oad } \\
8\end{array}$ \\
\hline 3 & $\begin{array}{c}\text { Load } \\
18 \\
\end{array}$ & $\begin{array}{c}\text { Load } \\
8 \\
\end{array}$ & Iord & & 16 & 24 & Ond & 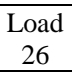 & $\begin{array}{l}\text { oad } \\
7 \\
\end{array}$ \\
\hline 4 & $\begin{array}{c}\text { Load } \\
4\end{array}$ & I & & & Ion & & & & $\begin{array}{c}\text {-oad } \\
3 \\
\end{array}$ \\
\hline 5 & $\begin{array}{c}\text { Load } \\
16\end{array}$ & & Iop & & It & & 27 & & $\begin{array}{l}\text { Load } \\
4 \\
\end{array}$ \\
\hline 6 & $\begin{array}{c}\text { Load } \\
26\end{array}$ & & & & & & $I_{\mathrm{S}}$ & & $\begin{array}{l}\text { Load } \\
18\end{array}$ \\
\hline 7 & $\begin{array}{c}\text { Load } \\
27\end{array}$ & & $\begin{array}{c}\text { Loac } \\
3\end{array}$ & $\mathrm{Loa}$ & $\begin{array}{c}\text { Load } \\
3 \\
\end{array}$ & $I_{0}$ & $\begin{array}{c}\text { Load } \\
16 \\
\end{array}$ & & $\begin{array}{c}\text { Load } \\
25 \\
\end{array}$ \\
\hline 8 & $\begin{array}{c}\text { Load } \\
15\end{array}$ & & & & oad & & & & \\
\hline 9 & $\begin{array}{c}\text { Load } \\
24\end{array}$ & & Loac & & Load & & & & $\begin{array}{c}\text { Load } \\
15 \\
\end{array}$ \\
\hline 10 & $\begin{array}{c}\text { Load } \\
8\end{array}$ & & & & Load & & 8 & & $\begin{array}{c}\text { Load } \\
27\end{array}$ \\
\hline 11 & $\begin{array}{c}\text { Load } \\
7\end{array}$ & Load & $\begin{array}{c}\text { Load } \\
26\end{array}$ & & Load & & $\begin{array}{c}\text { Load } \\
7 \\
\end{array}$ & & $\begin{array}{c}\text { Load } \\
24 \\
\end{array}$ \\
\hline 12 & $\begin{array}{c}\text { Load } \\
21 \\
\end{array}$ & $\begin{array}{c}\text { Load } \\
21 \\
\end{array}$ & $I$ & & d & 8 & $\begin{array}{c}\text { Load } \\
21 \\
\end{array}$ & d & $\begin{array}{l}\text { Load } \\
26\end{array}$ \\
\hline 13 & $\begin{array}{c}\text { Load } \\
39 \\
\end{array}$ & $\begin{array}{c}\text { Load } \\
26 \\
\end{array}$ & $\begin{array}{c}\text { Load } \\
8 \\
\end{array}$ & Load & $\begin{array}{c}\text { Load } \\
7 \\
\end{array}$ & oad & $\begin{array}{c}\text { Load } \\
39 \\
\end{array}$ & Load & $\begin{array}{c}\text { Load } \\
21 \\
\end{array}$ \\
\hline 14 & $\begin{array}{c}\text { Load } \\
23\end{array}$ & & $\begin{array}{c}\text { Load } \\
7 \\
\end{array}$ & & Load & & Load & & $\begin{array}{l}\text { Load } \\
12 \\
\end{array}$ \\
\hline 15 & \begin{tabular}{|c|} 
Load \\
12
\end{tabular} & $\begin{array}{c}\text { Load } \\
39\end{array}$ & $\begin{array}{c}\text { Load } \\
12 \\
\end{array}$ & & $\begin{array}{c}\text { Load } \\
12\end{array}$ & $\begin{array}{c}\text { Load } \\
12\end{array}$ & Load & Load & Load \\
\hline 16 & $\begin{array}{c}\text { Load } \\
28\end{array}$ & & Load & & $\begin{array}{c}\text { Load } \\
39 \\
\end{array}$ & & Load & & $\begin{array}{c}\text { Load } \\
20 \\
\end{array}$ \\
\hline 17 & $\begin{array}{c}\text { Load } \\
29\end{array}$ & $\begin{array}{c}\text { Load } \\
28\end{array}$ & $\begin{array}{c}\text { Load } \\
28\end{array}$ & & $\begin{array}{c}\text { Load } \\
28\end{array}$ & Load & Load & & $\begin{array}{c}\text { Load } \\
28\end{array}$ \\
\hline 18 & Load & $\begin{array}{c}\text { Load } \\
29 \\
\end{array}$ & $\begin{array}{c}\text { Load } \\
29 \\
\end{array}$ & $\begin{array}{c}\text { Load } \\
29 \\
\end{array}$ & $\begin{array}{c}\text { Load } \\
29 \\
\end{array}$ & $\begin{array}{c}\text { Load } \\
29 \\
\end{array}$ & $\begin{array}{c}\text { Load } \\
20 \\
\end{array}$ & $\begin{array}{c}\text { Load } \\
20 \\
\end{array}$ & Load \\
\hline
\end{tabular}

Explanation: According to the suggested strategy table above, if there is a fault at generator 30, the load shedding order will be Load $25 \rightarrow$ Load $3 \rightarrow$ Load $18 \rightarrow \ldots$ until the system is stabilized again. Similarly, for the remaining generators.

B. Test load shedding on the IEEE 39 bus New England by Powerwold.

Process simulation sampling with the IEEE 10 generators 39 bus are made as follows:

Assuming the fault generator is 34 , at load level $100 \%$, the frequency and deviation of the rotor angle become unstable.
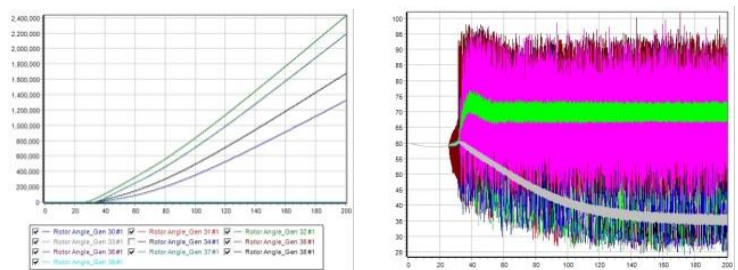

Fig. 12. Diagram of rotor angle generator and frequency of bus at fault generator 34 load level 100\%

When the bus frequency and rotor angle exceeded the allowable range, load shedding are made according to the strategic proposed. In this case, just shed the Load 20, the rotor frequency and angle have stabilized. 

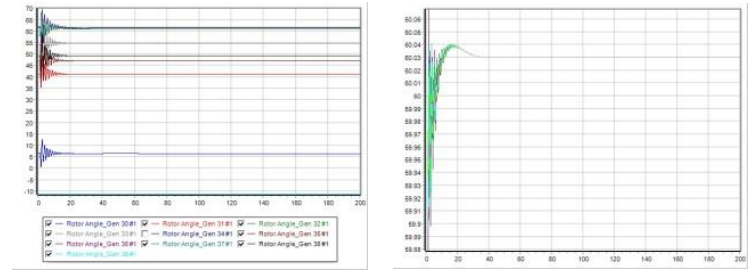

Fig. 13. Diagram of rotor angle generator and frequency of bus after shed Load 20

Simulation proceeds from $60 \%$ to $100 \%$ load level at each load level causing the outage generators from generator 30 to 39. After simulating and load shedding, the record is aggregated into sample. The result of the number of samples after the simulation of the case must load shedding when the generator fault is 369 samples.

\section{Neural network training}

This section introduces the generalized regression neural network training model; the training process follows these steps:

Step 1: Data collection, performs the collection via simulation on the PowerWorld software to retrieve data for each load level. Compile into a dataset, then split $85 \%$ of the sample for training and $15 \%$ of the sample for testing.

Step 2: Create a network, implementing generalized regression neural network training should provide only input and output vector information along with spread constant, the procedure as follows:

Create input_data is $85 \%$ of the samples (315 samples), output_data, input_test is $15 \%$ of the samples (54 samples).

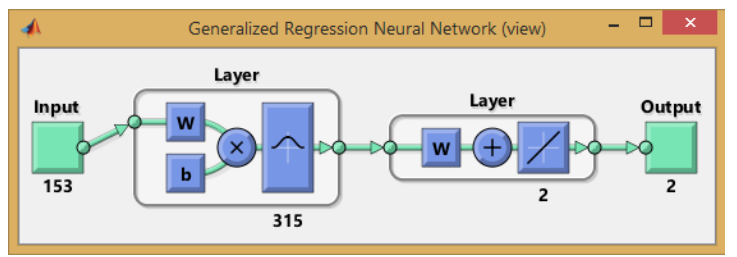

Fig. 14. Neural network training structure

Step 3: Create a interface.

To facilitate training, monitoring, fault identification and load shedding. The creation of an appropriate interface program is necessary to enable the operator to easily monitor the operation of the system. Combined with the idea of creating a machine system that works on different power systems the interface is created as follows:

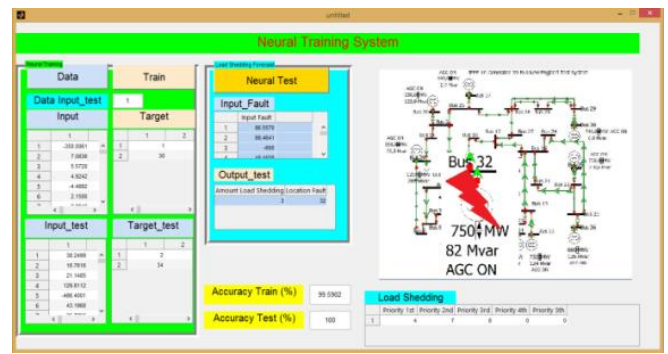

Fig. 15. The neural training system interface forecast load shedding in case of generator failure

\section{COMPARISON OF SUGGESTED METHOD WITH OTHER METHODS.}

A. Load shedding based on the AHP algorithm (Analytic Hierarchy Process) [6]

AHP is the approach to making decisions. This method presents balanced assessment options and criteria, and integrates them into a final decision. AHP is particularly suitable for cases involving analysis and quantification, make decisions when there are multiple options depending on the criteria with multiple interactions.

Table 3. The order of load shedding according to the AHP algorithm

\begin{tabular}{|c|c|c|c|c|c|}
\hline Order & Load & load center & $\mathbf{W}_{\mathbf{d i}}$ & $\mathbf{W}_{\mathbf{k j}}$ & $\mathbf{W}_{\mathbf{i j}}$ \\
\hline 19 & L39 & LC1 & 0.37 & 0.467 & 0.172543 \\
\hline 18 & L4 & LC1 & 0.22 & 0.467 & 0.104727 \\
\hline 17 & L8 & LC1 & 0.22 & 0.467 & 0.104727 \\
\hline 16 & L20 & LC2 & 0.3 & 0.278 & 0.08208 \\
\hline 15 & L7 & LC1 & 0.13 & 0.467 & 0.061118 \\
\hline 14 & L27 & LC3 & 0.33 & 0.16 & 0.053155 \\
\hline 13 & L29 & LC3 & 0.33 & 0.16 & 0.053155 \\
\hline 12 & L15 & LC2 & 0.17 & 0.278 & 0.048329 \\
\hline 11 & L16 & LC2 & 0.17 & 0.278 & 0.048329 \\
\hline 10 & L3 & LC4 & 0.49 & 0.10 & 0.047017 \\
\hline 9 & L24 & LC2 & 0.16 & 0.278 & 0.043056 \\
\hline 8 & L28 & LC3 & 0.20 & 0.16 & 0.031606 \\
\hline 7 & L21 & LC2 & 0.11 & 0.278 & 0.030445 \\
\hline 6 & L25 & LC4 & 0.31 & 0.10 & 0.029619 \\
\hline 5 & L23 & LC2 & 0.09 & 0.278 & 0.025351 \\
\hline 4 & L26 & LC3 & 0.14 & 0.16 & 0.022349 \\
\hline 3 & L18 & LC4 & 0.2 & 0.10 & 0.018659 \\
\hline 2 & L12 & LC1 & 0.03 & 0.467 & 0.011867 \\
\hline 1 & L31 & LC1 & 0.03 & 0.467 & 0.011867 \\
\hline
\end{tabular}

B. Load shedding based on under frequency load shedding relays [7]

Load shedding based on under frequency load shedding relays is the most commonly used method, which is still being used in many parts of the world, including Vietnam. When the grid frequency falls below the permitted threshold, the relay will be load shedding, prevents the system frequency declines. Without this load shedding control, the greatest possible consequence is the blackout, ie, the widespread outage.

For example, the ERCOT load shedding program, has a load shedding plan under frequency load shedding shown in Table 4.

Table 4. The ERCOT load shedding program

\begin{tabular}{|c|c|}
\hline Frequency & Load \\
\hline $59.3 \mathrm{~Hz}$ & $5 \%$ of total load \\
\hline $58.9 \mathrm{~Hz}$ & $15 \%$ of total load \\
\hline $58.5 \mathrm{~Hz}$ & $25 \%$ of total load \\
\hline
\end{tabular}

C. Simulate and compare methods with each other.
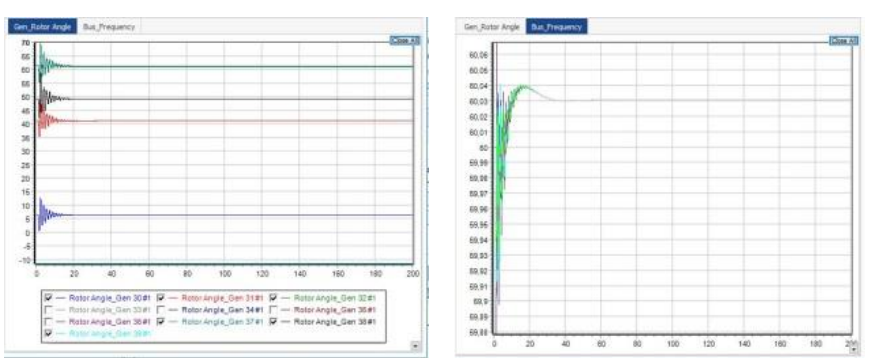

Fig. 16. Diagram of rotor angle and bus frequency after generator 34 outage according to the proposed load shedding method. 

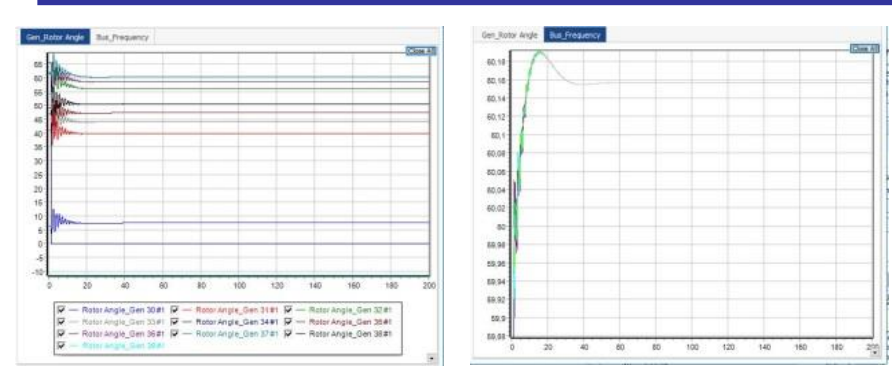

Fig. 17. Diagram of rotor angle and bus frequency after generator 34 outage according to the AHP method.
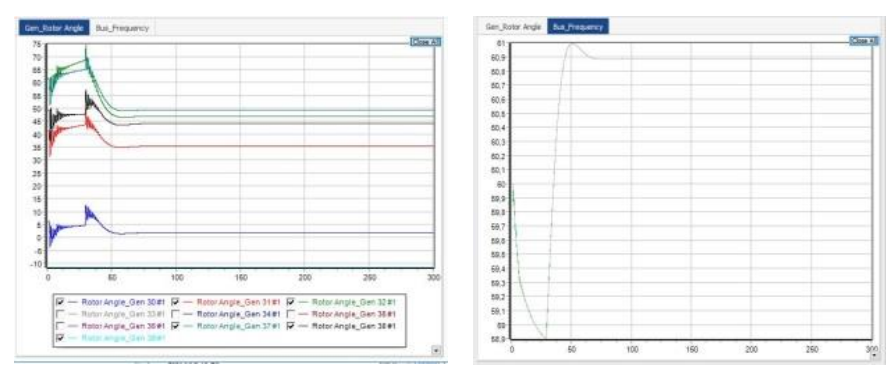

Fig. 18. Diagram rotor angle and bus frequency after generator 34 outage according to the under frequency load shedding relay method.

Comparative results of the methods presented in Table 5 .

Table 5. Comparative results of the methods
\begin{tabular}{|c|c|c|c|}
\hline Method & $\begin{array}{c}\text { Frequency } \\
\text { recovery time } \\
(\mathrm{s})\end{array}$ & $\begin{array}{c}\text { Frequency } \\
\text { stability } \\
(\mathrm{Hz})\end{array}$ & $\begin{array}{c}\text { Amount of } \\
\text { load shedding } \\
(\mathrm{MW})\end{array}$ \\
\hline Proposed & 45 & 60,030 & 628,000 \\
\hline AHP & 55 & 60,157 & 738,852 \\
\hline UFLS relay & 100 & 60,89 & 1154,394 \\
\hline
\end{tabular}

In the case of generators 34 outage with a load level of $100 \%$, the proposed method has many advantages over the AHP method and the low frequency method, as follows:

The amount of load shedding in at least 3 methods.

The rotor angle recovery time is almost the same, but the frequency recovery time of the proposed method is earlier (about $20 \div 25$ s). System stability sooner and increased reliability in the supply.

It can be seen that the load shedding is based on phase electrical distance are offset for both the remaining methods, with fast recovery times, optimum capacity load shedding and bus frequencies within the allowable range.

\section{CONCLUSION.}

The paper proposed the method load shedding on the basis of the combination of Generalized Regression Neural Network, power sensitivity theory and Phase Electrical Distance theories to maintain a stable electrical system in the event loss a generator occurring in the electric system. The effect of the proposed method is to perform offline simulations on the IEEE 39 Bus New England test system. The results of the comparison of the efficacy of the proposed method with the AHP method and low frequency method revealed that: The proposed method has a system frequency of recovery that is $18 \%$ faster than the AHP method, 55\% faster than the low frequency method; The load shedding capacity was $15 \%$ less than the AHP method and $45.6 \%$ less than the under frequency load shedding relay method.

\section{ACKNOWLEDGMENT}

This research was supported by Ho Chi Minh City University of Technology and Education under a research at the Power System and Renewable Lab.

\section{REFERENCES}

[1] H. Bevrani, Senior Member, IEEE, G. Ledwich, Senior Member, IEEE, and J. J. Ford. "On the Use of df/dt in Power System Emergency Control", 2009.

[2] Urban Rudez, Rafael Mihalic, Faculty of Electrical Engineering, University of Ljubljana, Trzaska 25, 1000 Ljubljana, Slovenia. "A novel approach to underfrequency load shedding", 2011.

[3] Farrokh Shokooh, J.J. Dai, Shervin Shokooh, Jacques Tastet, Hugo Castro, Tanuj Khandelwal, \& Gary Donner, IEEE Industry Applications Magazine, "Intelligent load shedding, case study of the application in a large industrial facility", 21 January 2011.

[4] Lagonotte Patrick, Labroratoire d'Automaticque et d'Informatique Industrielle, "The different electrical distances"

[5] Tohid Shekari, Student Member, IEEE, Farrokh Aminifar, Senior Member, IEEE, and Majid Sanaye-Pasand, Senior Member, IEEE, "An Analytical Adaptive Load Shedding Scheme Against Severe Combinational Disturbances", 2015

[6] Nhan MaiNgoc, "Master Thesis: Study of load shedding using neural network and AHP algorithm", Ho Chi Minh City of University of Technology and Education, VietNam, 2017

[7] Ercot, "Under frequency Load Shedding, 2006

[8] D. Kottick, "Neural Network for Predicting the Operation of an Under Frequency Load Shedding System", IEEE Trans. on Power Systems, Vol.11, No. 3, pp. 1350-58, 1996. 